\title{
High dose versus low dose standardized cranberry proanthocyanidin extract for the prevention of recurrent urinary tract infection in healthy women: a double-blind randomized controlled trial
}

Asma Babar ${ }^{1,2}$, Lynne Moore $^{2}$, Vicky Leblanc 3 , Stéphanie Dudonné ${ }^{3}, Y_{v e s}$ Desjardins ${ }^{3}$, Simone Lemieux ${ }^{3}$, Valérie Bochard ${ }^{4}$, Denis Guyonnet ${ }^{5}$ and Sylvie Dodin ${ }^{1,2,6^{*}}$

\begin{abstract}
Purpose: Our objective was to assess the efficacy of a high dose cranberry proanthocyanidin extract for the prevention of recurrent urinary tract infection.

Material and methods: We recruited 145 healthy, adult women with a history of recurrent urinary tract infection, defined as $\geq 2$ in the past 6 months or $\geq 3$ in the past 12 months in this randomized, controlled, double-blind clinical trial. Participants were randomized to receive a high dose of standardized, commercially available cranberry proanthocyanidins $(2 \times 18.5 \mathrm{mg}$ daily, $\mathrm{n}=72)$ or a control low dose $(2 \times 1 \mathrm{mg}$ daily, $n=73)$ for a 24 -week period. During followup, symptomatic women provided urine samples for detection of pyuria and/or bacteriuria and received an appropriate antibiotic prescription. The primary outcome for the trial was the mean number of new symptomatic urinary tract infections during a 24-week intervention period. Secondary outcomes included symptomatic urinary tract infection with pyuria or bacteriuria.
\end{abstract}

Results: In response to the intervention, a non-significant $24 \%$ decrease in the number of symptomatic urinary tract infections was observed between groups (Incidence rate ratio $0.76,95 \% \mathrm{Cl} 0.51-1.11$ ). Post-hoc analyses indicated that among 97 women who experienced less than 5 infections in the year preceding enrolment, the high dose was associated with a significant decrease in the number of symptomatic urinary tract infections reported compared to the low dose (age-adjusted incidence rate ratio $0.57,95 \% \mathrm{Cl} 0.33-0.99$ ). No major side effects were reported.

Conclusion: High dose twice daily proanthocyanidin extract was not associated with a reduction in the number of symptomatic urinary tract infections when compared to a low dose proanthocyanidin extract. Our post-hoc results reveal that this high dose of proanthocyanidins may have a preventive impact on symptomatic urinary tract infection recurrence in women who experienced less than 5 infections per year.

Trial registration: Clinicaltrials.gov, identifier NCT02572895

Keywords: Women, Urinary tract infections, Proanthocyanidins, Cranberry, Prevention

*Correspondence: sylvie.dodin@fmed.ulaval.ca

${ }^{1}$ CHU de Québec-Laval University Research Center, Québec City, Canada

Full list of author information is available at the end of the article

(c) The Author(s) 2021. Open Access This article is licensed under a Creative Commons Attribution 4.0 International License, which permits use, sharing, adaptation, distribution and reproduction in any medium or format, as long as you give appropriate credit to the original author(s) and the source, provide a link to the Creative Commons licence, and indicate if changes were made. The images or other third party material in this article are included in the article's Creative Commons licence, unless indicated otherwise in a credit line to the material. If material is not included in the article's Creative Commons licence and your intended use is not permitted by statutory regulation or exceeds the permitted use, you will need to obtain permission directly from the copyright holder. To view a copy of this licence, visit http://creativecommons.org/licenses/by/4.0/. The Creative Commons Public Domain Dedication waiver (http://creativeco mmons.org/publicdomain/zero/1.0/) applies to the data made available in this article, unless otherwise stated in a credit line to the data. 


\section{Introduction}

Urinary tract infection (UTI) is one of the main reasons for emergency medical consultation. One in three women over the age of 18 will experience a UTI, and many of them will have repeated infections [1]. Increasing resistance of pathogens to prescribed antibiotics, both in treatment and prophylaxis, as well as the side effects of antibiotics, reinforce the demand for alternatives that are effective and well tolerated [2].

Cranberry products are the most promising natural health alternatives for the prevention of UTIs [3]. Cranberry has been shown to inhibit the adhesion of uropathogenic Escherichia coli to uroepithelial cells [4]. In vitro, cranberry proanthocyanidins (PACs) with type A-linkages, have been identified as responsible for this anti-adhesion effect [5]. Clinical trials have been conducted to test the efficacy of cranberry products, mainly in the form of juices, but their results remain discordant [3]. This discrepancy is mainly explained by a lack of compliance, lack of statistical power and variable PAC concentrations in the tested products. Indeed, PAC concentrations are not disclosed in the majority of clinical trials. According to ex vivo clinical studies (dose-effect studies evaluating the optimal dose for urine anti-adhesion effect), the quantification of PACs requires standardized, reproducible methods and should be at least $36 \mathrm{mg} /$ day $[5,6]$. We hypothesize that the efficacy of cranberry products on the prevention of recurrent UTIs in women could be improved with the use of an optimal PACs dose (standardized at $2 \times 18.5 \mathrm{mg} /$ day).

\section{Materials and methods}

The Cranberry Extract for Prevention of Recurrent UTI Trial (PACCANN) was a randomized, double blind, controlled, clinical trial performed at the Institute of Nutrition and Functional Foods (INAF). The study was conducted according to the guidelines of the Helsinki Declaration (2013 revision). The protocol, consent form and all procedures were approved by the institutional ethics committee of Laval University. Written informed consent was obtained from all study participants. The protocol was registered on ClinicalTrials.gov on October 9, 2015 (NCT02572895) and has been published in BMC Urology [7].

\section{Study population}

We enrolled sexually active non-pregnant women aged 18 years and over presenting with recurrent UTI as diagnosed by a physician (defined as $\geq 2$ UTIs in the past 6 months or $\geq 3$ UTIs in the past 12 months). Women were recruited in the Laval University community in Quebec City, Canada, through e-mail list serves and local clinician referrals as well as posters in medical clinics, social media, paid advertising and word of mouth. Eligibility of potential participants was verified by the study coordinator according to inclusion and exclusion criteria (Table 1). The risks and benefits of the study have been thoroughly discussed and the consent form was signed at the first of three visits at INAF.

\section{Study product}

The high dose intervention consisted of twice daily intake of commercially available $120 \mathrm{mg}$ Urophenol $^{\mathrm{TM}}$, a purified cranberry extract from whole fruit (Vaccinium macrocarpon Aiton) standardized at min 15\% PACs. The control dose was standardized at $1 \%$ PACs which is comparable to the majority of cranberry products approved by Health Canada [8]. Cranberry PACs were manufactured by Nutra Canada (now part of Diana Food Canada) and similar in size, smell and taste. Capsules were distributed in opaque packaging in order to conceal slight colour variations from the research team. Total PAC content of each treatment was validated at INAF's analytical laboratory using the 4-dimethylaminocinnamaldehyde (BL-DMAC) method [9] ("Appendix 1"). PACs were also characterized by normal-phase analytical HPLC coupled with fluorescence detection, as previously described [10].

\section{Randomization}

Concealed randomization was generated using computer assisted randomization by blocks of 10 . Eligible women were assigned 1:1 to either high PAC $(2 \times 18.5 \mathrm{mg}$ capsules per day) or low PAC $(2 \times 1 \mathrm{mg}$ capsules per day $)$ content cranberry capsules for 24 weeks. All clinical investigation, laboratory analysis, data collection and assessment were blinded to the randomization allocation.

Table 1 Admissibility criteria

Inclusion criteria
Sexually active healthy women
Aged 18 years and older
Recent history of recurrent urinary tract infections ${ }^{\text {a }}$
$\geq 2$ UTIs in the past 6 months and/or
$\geq 3$ UTIs in the past 12 months
No consumption of cranberry product, polyphenol or antioxidant supple-
ments in the last 2 weeks
Exclusion criteria
Pregnancy
History of anatomical urogenital anomalies, urogenital tract surgery
History of acute or chronic renal failure, nephrolithiasis
History of intestinal diseases causing malabsorption
Anticoagulant medication in the last month
Known allergy or intolerance to cranberry

a UTIs diagnosed by a clinician and treated with antibiotic therapy 


\section{Clinical follow-up}

Each visit (0, 12 and 24 weeks) included a short questionnaire documenting socio-demographic characteristics $(\mathrm{T}=0$ only), medication and natural health product intake, quality of life (SF-12) [11], risk factors for UTIs, and a validated food frequency questionnaire [12] modified for our study to specifically include sixty-one foods containing PACs. Participants were instructed to obtain a midstream urine sample on which dipstick urinalysis and pregnancy tests were performed.

During their participation, women were asked to contact the study coordinator if they presented symptoms of UTI to schedule a visit at INAF in order to confirm the clinical diagnosis, provide a urine sample and receive an appropriate antibiotic prescription. A dipstick urinalysis using Chemstrip 9 (Roche Diagnostics USA) was used to confirm pyuria and urine samples were outsourced to the Laval University Hospital Center microbiology laboratory for culture. In line with the pragmatic aspect of this trial, women who were unable to present themselves to the research facility during a symptomatic episode were provided with an empiric antibiotic by prescription of the clinician.

Women that discontinued the intervention were asked to present themselves at the 12 and 24-week visit to complete intention to treat analysis. All participants were asked not to consume other products containing cranberry derivatives for the duration of the study.

\section{Outcomes}

The primary outcome was the number of symptomatic UTIs during the 24-week follow-up period. Symptomatic UTI was defined as acute urinary symptoms such as urine frequency, urgency, dysuria, pelvic pain, and hematuria in the absence of alternate diagnoses as assessed by study staff. The choice of symptomatic UTI was based on local [13] and international guidelines [14] as well as on realistic clinical settings in North America where empirical therapy is prescribed on the basis of clinical symptoms [14]. This outcome increased our capture of UTI episodes and trial conduct as we anticipated that certain women would be unable to present themselves to the research facilities to provide a urine sample.

Secondary outcomes were symptomatic UTI with pyuria and symptomatic UTI with bacteriuria. Women who presented both symptoms and a positive leukocyte esterase dipstick result, were diagnosed as having symptomatic UTI with pyuria. Episodes were categorized as symptomatic UTI with bacteriuria in the presence of $\geq 10^{3} \mathrm{CFU} / \mathrm{ml}$ of uropathogenic bacteria. Women with antibiotic treatment for symptomatic UTI during the study period continued to take the cranberry capsules and remained in the study for 24 weeks.

\section{Compliance and side effects}

Participants completed a daily journal to record compliance and were asked to bring capsule bottles to each visit in order to count remaining capsules. A bi-weekly email reminder was sent to encourage participation. Side effects were evaluated at each visit and participants were asked to document symptoms in their daily journal.

\section{Sample size and statistical analysis}

We estimated that $35 \%$ of patients in the control group would present at least one UTI during the 24-week follow-up period [3]. We needed to recruit 126 women to detect a clinically significant difference of $25 \%$ between the 2 groups ( $10 \%$ of women assigned to the experimental group would experience at least 1 UTI with a power of $80 \%$ ). We estimated that $15 \%$ of randomized participants would be lost to follow-up [15], therefore 148 women needed to be recruited in order for at least 126 participants to complete the 24-week intervention.

The Poisson regression model was used to compare the incidence of symptomatic UTI during the 24-week follow-up. A Kaplan Meier estimate with a log-rank test was used to compare time to first UTI between the two treatment arms. Intention to treat analyses were performed in all randomly assigned subjects with the observation time censored at the date that the participant abandoned or the date of last contact (either a scheduled study visit or visit for UTI treatment). All statistical analyses were performed using SAS University Edition software (SAS Institute Inc., Cary, NC, USA).

\section{Post-hoc and sensitivity analysis}

In the case of imbalanced groups, we generated relative rate estimates adjusted for potential confounding variables. Univariate regression analyses were performed for relevant variables collected at the baseline visit and data collected from post-hoc questions. Missing data was excluded from analyses for post-hoc questions. Variables with a $p$ value $<0.20$ in univariate analysis were included in the multivariate regression model. Interactions with the treatment groups were tested in multivariate regression model using a backward elimination method. Interactions with a $p$ value $<0.05$ are presented in the results by subgroup of the effect-modifying factor.

The incidence of UTI with pyuria or bacteriuria was estimated using a statistical imputation method for missing urine samples with two extreme assumptions: symptomatic UTI episodes without urine samples were classified as (1) no symptomatic UTI with pyuria or bacteriuria; and (2) symptomatic UTI with pyuria or bacteriuria. 


\section{Results}

Between August 2015 and December 2016, 267 potential participants were assessed for eligibility, of which 122 were excluded mainly because they did not meet criteria for recurrent UTI (Fig. 1). From August 2015 to April
2017, 145 women were recruited and randomly assigned to consume the high dose or low dose PAC capsules for a 24-week period. Reasons for discontinuing the intervention and abandoning study are shown in Appendices 2 and 3 . The groups were well balanced in terms of

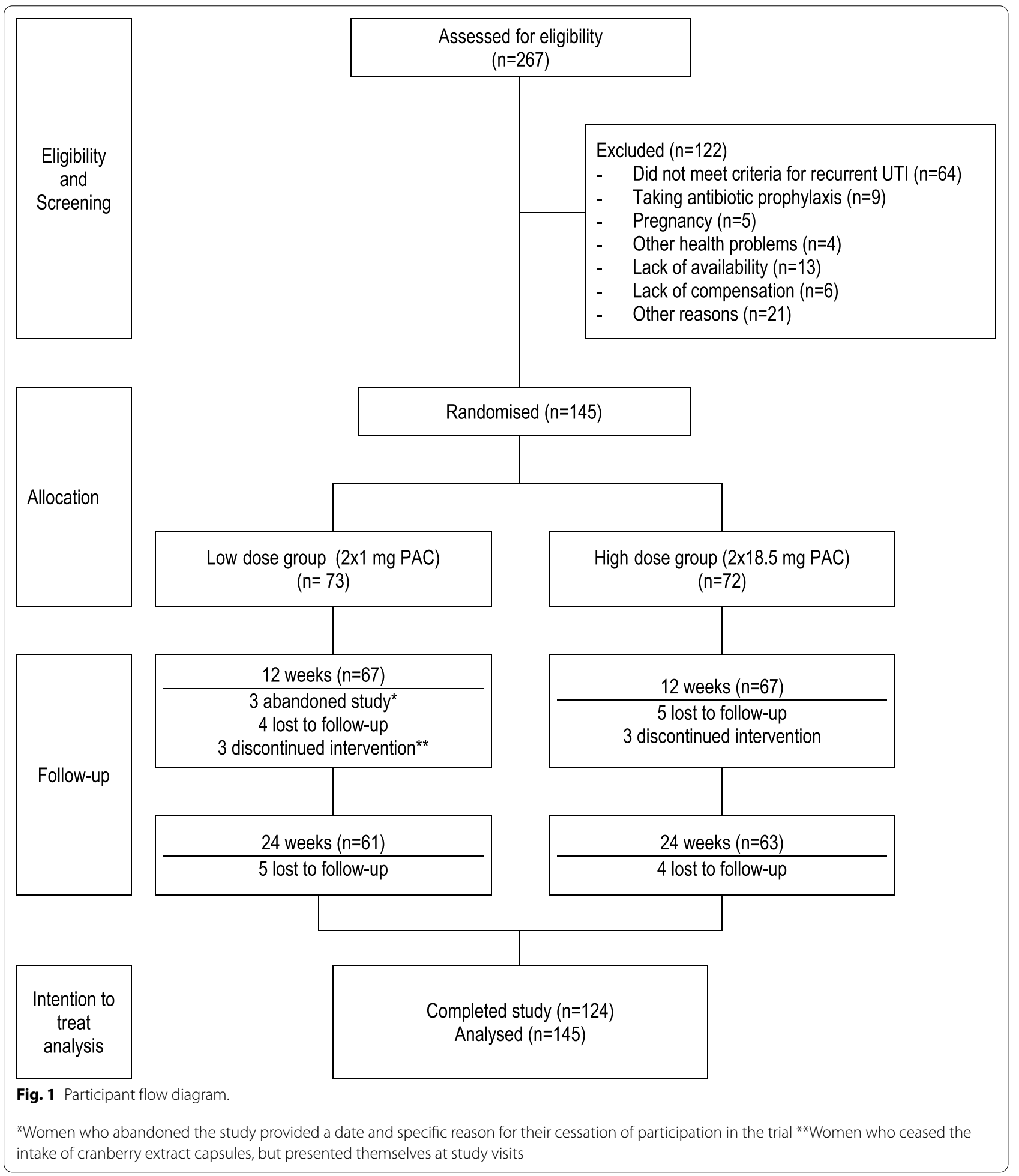


Table 2 Baseline demographic characteristics of participants by study arm

\begin{tabular}{|c|c|c|c|}
\hline Demographic characteristics & $\begin{array}{l}\text { Low dose } \\
\text { group, } \\
2 \times 1 \mathrm{mg} \\
\text { PAC }(n=73)\end{array}$ & $\begin{array}{l}\text { High dose } \\
\text { group, } \\
2 \times 18.5 \mathrm{mg} \\
\text { PAC }(n=72)\end{array}$ & $P^{*}$ \\
\hline Age $(\text { mean } \pm S D)^{* * * * *}$ & $32.5 \pm 14.2$ & $27.2 \pm 8.8$ & 0.009 \\
\hline Age subgroup, years, n (\%) & & & 0.028 \\
\hline $18-24$ years & $30(41.1)$ & $37(51.4)$ & \\
\hline $25-44$ years & $29(39.7)$ & $31(43.1)$ & \\
\hline$>45$ years & $14(19.2)$ & $4(5.6)$ & \\
\hline Age subgroup, years, n (\%) & & & 0.003 \\
\hline $18-51$ years & $62(84.9)$ & $71(98.6)$ & \\
\hline$>51$ years & $11(15.1)$ & $1(1.4)$ & \\
\hline Ethnic origin & & & 0.681 \\
\hline Caucasian & $65(89.0)$ & $65(90.3)$ & \\
\hline Non-Caucasian & $6(8.2)$ & $5(6.9)$ & \\
\hline Biracial & $2(2.7)$ & $2(2.8)$ & \\
\hline Marital status & & & 0.230 \\
\hline Single & $25(34.3)$ & $26(36.1)$ & \\
\hline Common law & $33(45.2)$ & $39(54.2)$ & \\
\hline Married & $13(17.8)$ & $7(9.7)$ & \\
\hline Divorced & $2(2.7)$ & $0(0)$ & \\
\hline Has children & $21(28.7)$ & $12(16.7)$ & 0.082 \\
\hline Living environment & & & 0.998 \\
\hline Urban & $50(68.5)$ & $49(68.1)$ & \\
\hline Suburban & $18(24.7)$ & $18(25)$ & \\
\hline Rural & $5(6.9)$ & $5(6.9)$ & \\
\hline Education & & & 0.814 \\
\hline University & $39(53.4)$ & $42(58.3)$ & \\
\hline College & 28 (38.4) & 24 (33.3) & \\
\hline Secondary school & $6(8.2)$ & $6(8.3)$ & \\
\hline
\end{tabular}

*Comparability of numerical and categorical baseline characteristics between groups was assessed with a student's t-test and ANOVA and chi-squared tests, respectively

**Numbers represent frequency (\%) unless otherwise indicated

***Significant difference between groups (student t-test, $p=0.009$ )

demographic (Table 2) and clinical (Table 3) characteristics. However, women randomized to the high dose group were significantly younger (mean age $27.2 \pm 8.8$ years old) than those randomized in the low dose group (mean age $32.5 \pm 14.2$ years old) (Student t-test, $p=0.009$ ).

\section{Symptomatic UTI}

A total of 45 symptomatic UTIs were diagnosed in the high dose PAC group compared to 59 in the low dose group. The annualized incidence rate of symptomatic UTI for women receiving $2 \times 18.5 \mathrm{mg}$ PACs at 24 weeks was 1.48 (95\%CI $1.11-1.99)$ compared to 1.96 (95\%CI $1.52-$ 2.53) in women receiving $2 \times 1 \mathrm{mg}$ PACs (Incidence rate ratio $($ IRR $)=0.76,95 \%$ CI 0.51-1.11; Table 4). UTI-free median was 24.0 weeks in the high dose group compared to 16.6 weeks in the low dose group. The hazard ratio for the difference between the number of subjects who had experienced a first symptomatic UTI by the end of the 24-week period was 0.73 (95\% CI 0.45-1.16; Fig. 2).

Univariate Poisson regression analysis for total number of symptomatic UTIs and known risk factors are shown in Table 5. After adjustment for age, only the number of UTI in the 12 months preceding enrolment showed a significant interaction between groups. Among participants with less than 5 UTIs in the 12 months preceding enrolment $(\mathrm{n}=97)$, the age-adjusted annualized incidence rate of UTI in the high dose group was 1.32 (95\%CI $0.81-2.13)$ compared to 2.29 (95\%CI $1.66-3.16)$ in the low-dose group (IRR $=0.57,95 \% \mathrm{CI} 0.33-0.99)$ (Table 6).

\section{Symptomatic UTI with pyuria}

Data were obtained from women who presented themselves to the research facility in order to provide a urine sample in 70 out of 104 symptomatic UTI episodes. Eighty-one percent of the 70 urine samples obtained presented pyuria as measured by a positive leucocyte esterase dipstick test. No statistically significant reductions in the incidence rate of symptomatic UTI with pyuria were found between treatment groups. In women with less than 5 UTIs in the 12 months prior to enrolment, the daily intake of $2 \times 18.5 \mathrm{mg}$ PAC, compared to $2 \times 1 \mathrm{mg}$ PAC, was associated with a statistically significant $47 \%$ reduction in the age-adjusted incidence rate of symptomatic UTI with pyuria (IRR $=0.54,95 \%$ CI $0.30-0.99$ ), where symptomatic UTI without urine samples were classified as symptomatic UTI with pyuria (Table 7)).

\section{Symptomatic UTI with bacteriuria}

Urine culture was performed in 61 of the 70 urine samples collected during symptomatic UTI. A positive culture was confirmed in $49 \%$ of the 61 urine samples analyzed during symptomatic UTI. No statistically significant reductions in the age-adjusted incidence rate of symptomatic UTI with bacteriuria were found between groups nor in sub-group analyses in women with less than 5 UTIs in the 12 months prior to enrolment (Table 8).

\section{Compliance, side effects and adherence to double-blind procedures}

Compliance based on number of returned capsules at 24 weeks was similar in both groups $(92.9 \%$ in the high dose group vs $92.7 \%$ in the low dose group, student t-test $p=0.9)$. Compliance according to daily intake journals was comparable in both groups, $87.3 \%$ in the high dose group and $88.8 \%$ in the low dose group (Student $\mathrm{t}$-test, $p=0.6$ ). No serious adverse events occurred in either of the study groups. The only reported side 
Table 3 Baseline clinical characteristics of participants by study arm

\begin{tabular}{|c|c|c|c|}
\hline Clinical characteristics & $\begin{array}{l}\text { Low dose group, } 2 \times 1 \mathrm{mg} \\
\text { PAC }(n=73)\end{array}$ & $\begin{array}{l}\text { High dose group, } 2 \times 18.5 \mathrm{mg} \\
\text { PAC }(n=72)\end{array}$ & $P$ value \\
\hline Number of episodes of UTI in the past 6 months** & & & 0.816 \\
\hline 1 & $13(17.8)$ & $8(11.1)$ & \\
\hline 2 & $34(46.6)$ & $37(51.4)$ & \\
\hline 3 & $17(23.3)$ & $16(22.2)$ & \\
\hline 4 & $6(8.22)$ & $7(9.7)$ & \\
\hline$\geq 5$ & $3(4.11)$ & $4(5.6)$ & \\
\hline Number of episodes of UTI in the past 12 months & & & 0.249 \\
\hline 2 & $13(17.8)$ & $7(9.72)$ & \\
\hline 3 & $22(30.1)$ & $29(40.3)$ & \\
\hline 4 & $11(15.1)$ & $15(20.8)$ & \\
\hline$\geq 5$ & $27(37.0)$ & $21(26.17)$ & \\
\hline Frequency of sexual intercourse (per week) & & & 0.304 \\
\hline$\leq 1$ & $22(30.1)$ & $14(19.4)$ & \\
\hline $2-4$ & $34(46.6)$ & $41(56.9)$ & \\
\hline $5-6$ & $10(13.7)$ & $13(18.1)$ & \\
\hline$\geq 7$ & $7(9.6)$ & $4(5.6)$ & \\
\hline Number of sexual partners & & & 0.256 \\
\hline 0 & $5(6.9)$ & $1(1.4)$ & \\
\hline 1 & $67(91.8)$ & $70(97.2)$ & \\
\hline 2 & $1(1.4)$ & $1(1.4)$ & \\
\hline Stability in sexual relations & & & 0.987 \\
\hline No stability & $3(4.1)$ & $2(1.4)$ & \\
\hline Stable in the past month & $7(9.6)$ & $6(8.3)$ & \\
\hline Stable in the past 6 months & $16(21.9)$ & $15(20.8)$ & \\
\hline Stable in the past year & $46(63.0)$ & $48(66.7)$ & \\
\hline Prefer not to respond & $1(1.4)$ & $1(1.4)$ & \\
\hline New partner in last month & $4(5.5)$ & $5(6.9)$ & 0.715 \\
\hline Type of Contraception & & & 0.373 \\
\hline Hormonal contraception & $43(58.9)$ & $53(73.6)$ & \\
\hline Spermicide & $1(1.4)$ & 0 & \\
\hline Non hormonal IUD & $7(9.6)$ & $4(5.6)$ & \\
\hline Condom & $17(23.3)$ & $11(15.3)$ & \\
\hline None & $5(6.8)$ & $4(5.6)$ & \\
\hline First UTI before age 15 & $15(20.6)$ & $16(22.2)$ & 0.839 \\
\hline Maternal history of UTI & $38(52.1)$ & $43(59.7)$ & 0.352 \\
\hline Personal history of recurrent UTI*** & & & 0.775 \\
\hline$<1$ year & $4(8.2)$ & $2(4.3)$ & \\
\hline $1-2$ years & $9(18.4)$ & $12(25.5)$ & \\
\hline $3-5$ years & $15(30.6)$ & $15(31.9)$ & \\
\hline $6-10$ years & $14(28.6)$ & $10(21.3)$ & \\
\hline$>10$ years & $7(14.3)$ & $8(17.0)$ & \\
\hline Missing data & 24 & 25 & \\
\hline Hydration (average litres of water per day) & & & 0.147 \\
\hline Mean $\pm S D$ & $1.62 \pm 0.75$ & $1.81 \pm 0.63$ & \\
\hline$<1$ & $9(15.8)$ & $4(7.0)$ & \\
\hline$\geq 1-2$ & $30(52.6)$ & $27(47.4)$ & \\
\hline$>2-3$ & $13(22.8)$ & $23(40.4)$ & \\
\hline$\geq 3$ & $5(8.8)$ & $3(7.0)$ & \\
\hline Missing data & 16 & 15 & \\
\hline
\end{tabular}


Table 3 (continued)

\begin{tabular}{lll}
\hline Clinical characteristics & $\begin{array}{l}\text { Low dose group, } 2 \times 1 \mathrm{mg} \\
\text { PAC }(\mathrm{n}=73)\end{array}$ & $\begin{array}{l}\text { High dose group, } 2 \times 18.5 \mathrm{mg} \\
\text { PAC }(\mathrm{n}=72)\end{array}$ \\
\hline $\begin{array}{ll}P \text { value* } \\
\text { Alcohol consumption (per week)*** }\end{array}$ & $7(12.7)$ & $15(25.9)$ \\
$<1$ & $28(50.9)$ & $21(36.2)$ \\
$1-3$ & $20(36.4)$ & $22(37.9)$ \\
$>4$ & 18 & 14 \\
Missing data & & \\
Tobacco use*** & $5(8.8)$ & $3(5.2)$ \\
Smoker & $52(91.2)$ & $55(94.8)$ \\
Non-smoker & 16 & 14 \\
Missing data & 16 & 0.448 \\
\hline
\end{tabular}

*Comparability of numerical and categorical baseline characteristics between groups was assessed with a student's t-test and ANOVA and chi-squared tests, respectively

**Numbers represent frequency (\%) unless otherwise indicated

***Factors questioned during the follow-up period with missing data indicated

Table 4 Incidence of symptomatic UTI at 24 weeks by study arm

\begin{tabular}{|c|c|c|c|c|}
\hline & $\begin{array}{l}\text { Low dose group, } 2 \times 1 \mathrm{mg} \\
\text { PAC }(n=73)\end{array}$ & $\begin{array}{l}\text { High dose group, } \\
2 \times 18.5 \mathrm{mg} \\
\text { PAC }(n=72)\end{array}$ & Incidence rate ratio $(95 \% \mathrm{Cl})$ & $p$ value \\
\hline \multicolumn{5}{|l|}{ Subjects reporting symptomatic UTI, episodes, n (\%) } \\
\hline 0 & $34(46.6)$ & $41(57.0)$ & & \\
\hline 1 & $26(35.6)$ & $21(29.2)$ & & \\
\hline 2 & $8(11.0)$ & $7(9.7)$ & & \\
\hline 3 & $4(5.5)$ & $2(2.8)$ & & \\
\hline 4 & $0(0.0)$ & $1(1.4)$ & & \\
\hline 5 & $1(1.4)$ & $0(0.0)$ & & \\
\hline$\geq 1$ & $39(53.4)$ & $31(43.1)$ & & \\
\hline Total symptomatic UTIs, episodes & 59 & 45 & & \\
\hline Follow-up, days (mean $\pm S D$ ) & $151 \pm 43$ & $154 \pm 39$ & & \\
\hline Total person-days & 10,997 & 11,088 & & \\
\hline UTI, annualized incidence density $(95 \% \mathrm{Cl})^{\mathrm{a}}$ & $1.96(1.52-2.53)$ & $1.48(1.11-1.99)$ & $0.76(0.51-1.11)$ & 0.16 \\
\hline UTI, age-adjusted annualized incidence density $(95 \% \mathrm{Cl})^{\mathrm{b}}$ & $2.28(1.74-2.98)$ & $1.93(1.36-2.72)$ & $0.85(0.57-1.26)$ & 0.42 \\
\hline
\end{tabular}

a $\mathrm{UTI}=$ urinary tract infection

b Incidence rate ratios and $P$ values for the number of UTIs per woman-year of observation were determined from the generalized linear model with the Poisson distribution specified

effect, dyspepsia, led to a discontinuation of the intervention of one participant in each group. Participants were asked if they were aware of which treatment group they were assigned to in order to validate the effectiveness of blinding procedures. The majority of women in both groups responded that they were unaware of group allocation as show in "Appendix 4".

\section{Discussion}

This randomized clinical trial is the first to evaluate the efficacy of a standardized split daily dose of $37 \mathrm{mg}$ cranberry PACs in capsule form on symptomatic UTI. It is of particular interest that this dose was compared to another cranberry extract containing a low concentration of PACs, as often found on the Canadian supplement market to prevent UTI. Our results indicate that the intake of $2 \times 18.5 \mathrm{mg}$ PACs daily was associated with a non-statistically significant $24 \%$ reduction in the risk of symptomatic UTI compared to a daily dose of $2 \times 1 \mathrm{mg}$ PACs during a 24-week follow-up period, similar to the results of a recent meta-analysis [16].

The present study is distinct given that we recruited according to a guideline-based definition of recurrent UTI [17]. Our cohort had a higher mean incidence of UTI prior to study enrolment (mean UTI $=2.4 / 6$ months and 3.9/1 year) compared to similar trials such as Maki 


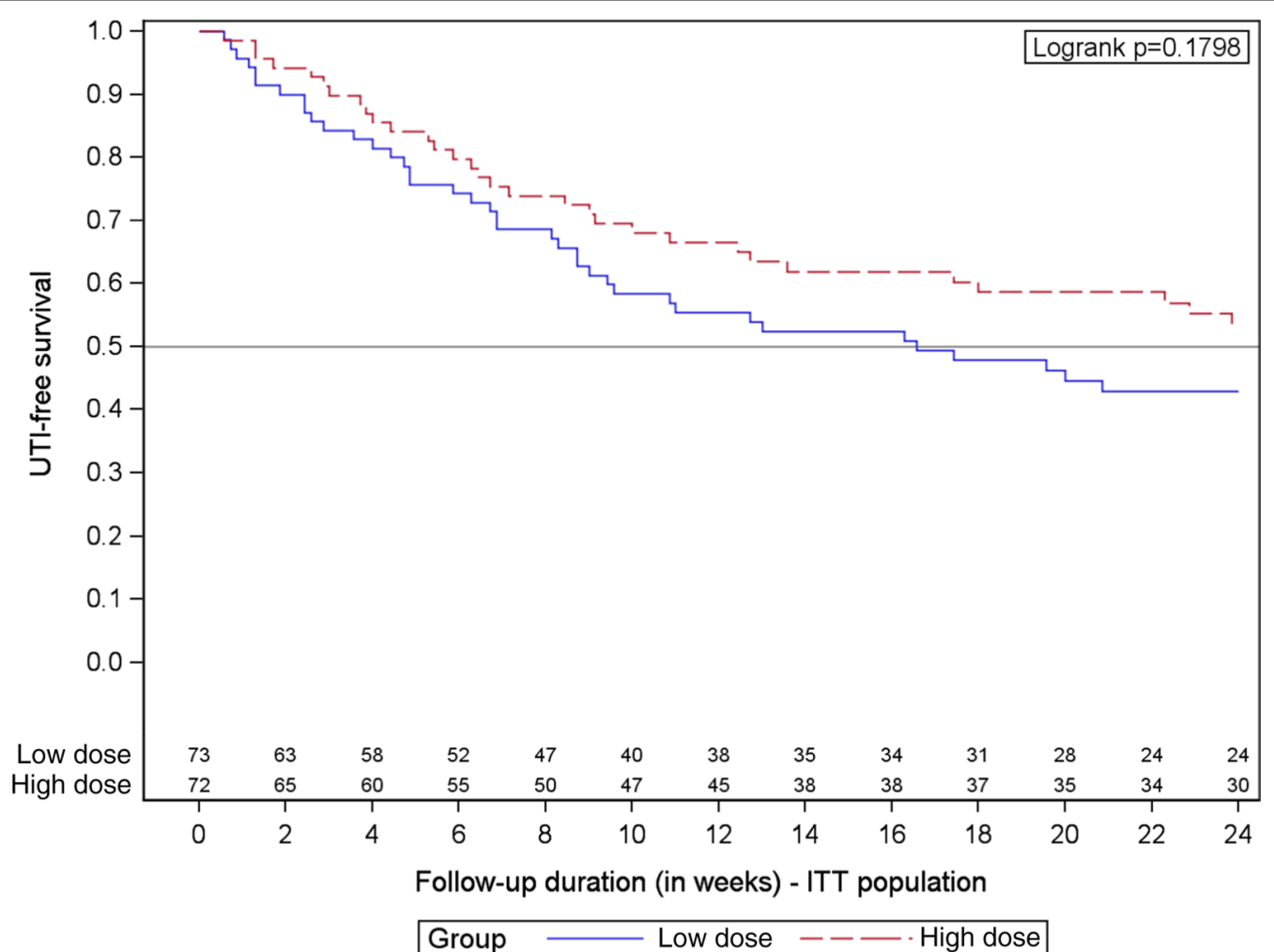

Fig. 2 Kaplan Meier analysis of survival to first UTI by treatment group

Table 5 Univariate poisson regression analysis of total number of symptomatic UTIs and baseline risk factors

\begin{tabular}{lc}
\hline Variable & $\begin{array}{c}p \text { value } \\
\text { Incidence rate ratio }(95 \% \text { Cl) }\end{array}$ \\
\hline Age (ref. =18-45 years) & $p=0.01$ \\
45 years and older & $1.97(1.25-3.11)$ \\
Number infections past 12 months (ref. $<5)$ & $p=0.02$ \\
$\geq 5$ & $1.62(1.1-2.39)$ \\
Frequency of sexual intercourse (per week) (ref. $<1)$ & $p=0.12$ \\
$2-4$ & $0.63(0.4-0.97)$ \\
$\geq 5-6$ & $0.78(0.46-1.32)$ \\
Hormonal contraception (ref.=no) & $p=0.84$ \\
Yes & $0.96(0.65-1.41)$ \\
Hydratation (average number of litres of liquid per day) (ref.<1 L/day) & $p=0.19$ \\
$1-2$ L/day & $0.57(0.32-1.02)$ \\
$\geq 2$ L/day & $0.66(0.36-1.18)$
\end{tabular}

et al. [18] (1.65/6 months), Barbosa-Cesnik et al. [19] (1.13 /1 year) or Stothers et al. [20] (2.8/1 year). The proportion of women in the $2 \mathrm{mg}$ PAC group that experienced more than 1 UTI (53.4\%) was also greater than the estimated 35\% [21] used to calculate our sample size. Considering these key differences with previous reports, we explored if UTI burden at baseline could impact the treatment effect. Statistical analysis confirmed that number of recurrent UTI was indeed a modifying factor. In women who experienced fewer than 5 UTI (mean number $=3.1$ ) in the year prior to enrolment, symptomatic UTIs were significantly reduced by $43 \%$. No significant effect was observed in women with higher past UTI burden. 
Table 6 Poisson regression sensitivity analysis of symptomatic UTIs by number of UTI prior to enrolment

\begin{tabular}{|c|c|c|c|}
\hline & $\begin{array}{l}\text { Low dose group, } \\
2 \times 1 \mathrm{mg} \text { PAC }\end{array}$ & $\begin{array}{l}\text { High dose group, } \\
2 \times 18.5 \mathrm{mg} \text { PAC }\end{array}$ & $\begin{array}{l}\text { Incidence rate ratio }(95 \% \mathrm{Cl}) \\
p \text { value }\end{array}$ \\
\hline Participants with less than 5 UTIs in the 12 months preceding enrolment & $n=46$ & $n=51$ & \\
\hline Number of symptomatic UTI & 39 & 21 & \\
\hline Symptomatic UTI, age-adjusted incidence density $(95 \% \mathrm{Cl})^{\mathrm{a}}$ & $2.29(1.66-3.16)$ & $1.32(0.81-2.13)$ & $\begin{array}{l}0.57(0.33-0.99) \\
p=0.048\end{array}$ \\
\hline Participants with 5 UTIs or more in the 12 months preceding enrolment & $n=27$ & $n=21$ & \\
\hline Number of symptomatic UTI & 20 & 24 & \\
\hline Symptomatic UTI, age-adjusted incidence density $(95 \% \mathrm{Cl})^{\mathrm{a}}$ & $2.23(1.37-3.61)$ & $3.34(1.96-5.68)$ & $\begin{array}{l}1.50(0.81-2.76) \\
p=0.195\end{array}$ \\
\hline
\end{tabular}

a Incidence rate ratios and $p$ value for symptomatic UTIs per woman-year of observation by number of UTI in the 12 months prior to enrolment (less than 5 UTIs vs greater than 5 UTIs) and adjusted for age group ( $<45$ years vs $\geq 45$ year)

In women experiencing higher level of UTI $(>5)$, certain factors that were not measured in our study could explain the mitigated response to PAC intake. It is possible that in these women, UTI recurrence may be the result of complex interactions between bacterial urovirulence and a particular host susceptibility (altered gut microbiota, less efficient adaptive immune response) [22-24]. Considering that PACs are poorly absorbed and are difficult to quantify in the urine, future studies should focus on the effect of these molecules on the gut microbiota, a natural reservoir for uropathogenic Escherichia coli $[22,25]$. Gut microbiota composition and function largely vary between individuals which might explain differences in individual's susceptibility to UTI. This could be mediated by a direct effect (e.g. growth inhibition of pathobiont [26], encroachment of uropathogenic bacteria in the gut) or an indirect effect (microbial metabolism of PAC or potential bioactive urinary metabolites). In order to provide mechanistic insight explaining different levels of recurrence, feces and urine samples are being analysed and results will be published in a future article.

Our study was based on medical practice in Quebec whereby many women receive antibiotics without delaying treatment for several days while awaiting urine culture results. Similarly, Maki et al. [18]. compared daily intake of $41 \mathrm{mg}$ PACs from cranberry juice cocktail compared to a placebo beverage on the incidence of symptomatic UTI during a 24-week follow-up. In our study, pyuria was present in $81 \%$ and bacteriuria was confirmed in $49 \%$ of the urine samples provided by participants during symptomatic UTI. This corresponds to the similar proportion of $80 \%$ of symptomatic UTI with pyuria and $60 \%$ with bacteriuria in a total of 106 symptomatic UTI episodes presented by Maki et al. [18].

This study had limitations that could influence our findings. The use of a control dose instead of placebo may explain why we were unable to find a significant reduction in the recurrence of UTI in our cohort with a high UTI burden. A study conducted by Vostavola et al. has shown that $2.8 \mathrm{mg}$ PAC daily can significantly impact the incidence of recurrent UTIs compared to placebo [27]. Moreover, urine cultures were incomplete for a proportion of urine samples provided by symptomatic participants. Urine culture contaminated by improper clean-catch urine technique were excluded from analyses in order to mitigate a risk of detection bias. We also experienced technical issues such as delays in delivery to the microbiology laboratory and improperly stored samples.

\section{Conclusions}

The intake of $2 \times 18.5 \mathrm{mg}$ PACs daily was associated with a non-statistically significant $24 \%$ reduction in the risk of symptomatic UTI compared to a daily dose of $2 \times 1 \mathrm{mg}$ PACs during a 24-week follow-up period. In a subset of participating women with a history of less than 5 UTIs per year, the daily consumption of $2 \times 18.5 \mathrm{mg}$ PACs resulted in a significant reduction in the rate of symptomatic UTI during the trial period compared to $2 \times 1 \mathrm{mg}$ PAC. These findings need to be tested in women with moderate burden of recurrent UTI who may benefit from a preventive treatment with a split dose of $37 \mathrm{mg} /$ day of PACs from cranberry extract, with few associated side effects. Further investigations are also needed to examine dose-dependent impacts of cranberry PACs for the prevention of recurrent UTI and their effects on the microbiota. 
Table 7 Incidence of symptomatic UTI with pyuria at 24 weeks by study arm

\begin{tabular}{|c|c|c|c|}
\hline & $\begin{array}{l}\text { Low dose } \\
\text { group, } \\
2 \times 1 \mathrm{mg} \text { PAC }\end{array}$ & $\begin{array}{l}\text { High dose group, } \\
2 \times 18.5 \mathrm{mg} \text { PAC }\end{array}$ & $\begin{array}{l}\text { Incidence rate ratio }(95 \% \mathrm{Cl}) \\
p \text { value }\end{array}$ \\
\hline Symptomatic UTI with pyuria, episodes, n (\%) & $n=73$ & $n=72$ & \\
\hline 0 & $50(68.5)$ & $53(73.6)$ & \\
\hline 1 & $17(23.3)$ & $14(19.4)$ & \\
\hline 2 & $5(6.8)$ & $4(5.6)$ & \\
\hline 3 & $0(0.0)$ & $0(0.0)$ & \\
\hline 4 & $1(1.4))$ & $1(1.4)$ & \\
\hline$\geq 1$ & $23(31.5)$ & $19(26.4)$ & \\
\hline Total symptomatic UTIs with pyuria, episodes & 31 & 26 & \\
\hline Total person-days & 10,997 & 11,088 & \\
\hline Symptomatic UTI with pyuria, annualized incidence density $(95 \% \mathrm{Cl})$ & $1.03(0.72-1.46)$ & $0.86(0.58-1.26)$ & $\begin{array}{l}0.83(0.49-1.40) \\
p=0.49\end{array}$ \\
\hline Symptomatic UTI with pyuria, age adjusted annualized incidence density $(95 \% \mathrm{Cl})$ & $1.24(0.86-1.77)$ & $1.21(0.77-1.89)$ & $\begin{array}{l}0.98(0.57-1.68) \\
p=0.94\end{array}$ \\
\hline Subgroup analyses In women with $<5$ UTI in past 12 months & $n=46$ & $n=51$ & \\
\hline Symptomatic UTI with pyuria & 21 & 12 & \\
\hline Symptomatic UTI with pyuria, annualized incidence density ( $95 \% \mathrm{Cl})$ & $1.05(0.60-1.50)$ & $0.55(0.24-0.87)$ & $\begin{array}{l}0.53(0.26-1.07) \\
p=0.08\end{array}$ \\
\hline Symptomatic UTI with pyuria, age-adjusted annualized incidence density $(95 \% \mathrm{Cl})$ & $1.27(0.82-1.95)$ & $0.83(0.44-1.54)$ & $\begin{array}{l}0.65(0.31-1.37) \\
p=0.26\end{array}$ \\
\hline Symptomatic UTI with pyuria, episodes, n (\%) ${ }^{b}$ & $n=73$ & $n=72$ & \\
\hline 0 & $39(53.4)$ & $45(62.5)$ & \\
\hline 1 & $23(31.5)$ & $18(25.0)$ & \\
\hline 2 & $6(8.2)$ & $7(9.7)$ & \\
\hline 3 & $4(5.5)$ & $1(1.4)$ & \\
\hline 4 & $0(0.0)$ & $1(1.4)$ & \\
\hline 5 & $1(1.4)$ & $0(0.0)$ & \\
\hline$\geq 1$ & $34(46.6)$ & $27(37.5)$ & \\
\hline Total symptomatic UTIs with pyuria, episodes & 52 & 39 & \\
\hline Total person-days & 10,997 & 11,088 & \\
\hline Symptomatic UTI with pyuria, annualized incidence density $(95 \% \mathrm{Cl})$ & $1.73(1.32-2.27)$ & $1.28(0.94-1.72)$ & $\begin{array}{l}0.74(0.49-1.13) \\
p=0.16\end{array}$ \\
\hline Symptomatic UTI with pyuria, age-adjusted annualized incidence density $(95 \% \mathrm{Cl})$ & $2.05(1.54-2.71)$ & $1.75(1.22-2.52)$ & $\begin{array}{l}0.86(0.56-1.32) \\
p=0.48\end{array}$ \\
\hline Subgroup analyses In women with $<5$ UTI in past 12 months & $n=46$ & $n=51$ & \\
\hline Symptomatic UTI with pyuria & 35 & 17 & \\
\hline Symptomatic UTI with pyuria, age-adjusted annualized incidence density (95\% Cl) & $1.75(1.26-2.20)$ & $0.78(0.41-1.16)$ & $\begin{array}{l}0.45(0.25-0.80) \\
p=0.01\end{array}$ \\
\hline Symptomatic UTI with pyuria, age-adjusted annualized incidence density (95\% CI) & $2.1(1.50-2.94)$ & $1.14(0.68-1.92)$ & $\begin{array}{l}0.54(0.30-0.99) \\
p=0.047\end{array}$ \\
\hline
\end{tabular}

\footnotetext{
a Symptomatic UTI episodes without urine sample were considered as no symptomatic UTI with pyuria
}

b Symptomatic UTI episodes without urine sample were considered as symptomatic UTI with pyuria 
Table 8 Incidence of symptomatic UTI with bacteriuria at 24 weeks by study arm

\begin{tabular}{|c|c|c|c|}
\hline & $\begin{array}{l}\text { Low dose } \\
\text { group, } \\
2 \times 1 \text { mg PAC }\end{array}$ & $\begin{array}{l}\text { High dose group, } \\
2 \times 18.5 \mathrm{mg} \text { PAC }\end{array}$ & $\begin{array}{l}\text { Incidence rate ratio }(95 \% \mathrm{Cl}) \\
p \text { value }\end{array}$ \\
\hline Symptomatic UTI with bacteriuria, episodes, n (\%) ${ }^{\mathrm{a}}$ & $n=73$ & $n=72$ & \\
\hline 0 & $55(75.3)$ & $63(87.5)$ & \\
\hline 1 & $17(23.3)$ & $7(9.7)$ & \\
\hline 2 & $1(1.4)$ & $2(2.8)$ & \\
\hline$\geq 1$ & $18(24.7)$ & $9(12.5)$ & \\
\hline Total symptomatic UTIs with bacteriuria, episodes & 19 & 11 & \\
\hline Total person-days & 10,997 & 11,088 & \\
\hline Symptomatic UTI with bacteriuria, annualized incidence density (95\% CI) & $0.63(0.40-0.99)$ & $0.36(0.20-065)$ & $\begin{array}{l}0.57(0.27-1.21) \\
p=0.14\end{array}$ \\
\hline $\begin{array}{l}\text { Symptomatic UTI with bacteriuria, age-adjusted annualized incidence density (95\% } \\
\text { CI) }\end{array}$ & $0.76(0.48-1.21)$ & $0.53(0.27-1.02)$ & $\begin{array}{l}0.69(0.32-1.49) \\
p=0.34\end{array}$ \\
\hline Subgroup analyses In women with $<5$ UTI in past 12 months & $n=46$ & $n=51$ & \\
\hline Symptomatic UTI with bacteriuria & 14 & 5 & \\
\hline Symptomatic UTI with bacteriuria, annualized incidence density (95\% Cl) & $0.70(0.42-1.18)$ & $0.23(0.10-0.55)$ & $\begin{array}{l}0.33(0.12-0.91) \\
p=0.03\end{array}$ \\
\hline $\begin{array}{l}\text { Symptomatic UTI with bacteriuria, age-adjusted annualized incidence density (95\% } \\
\text { CI) }\end{array}$ & $0.85(0.50-1.43)$ & $0.35(0.14-0.89)$ & $\begin{array}{l}0.41(0.14-1.19) \\
p=0.10\end{array}$ \\
\hline \multicolumn{4}{|l|}{ Subjects reporting symptomatic UTI with bacteriuria, episodes, n \%) } \\
\hline 0 & $42(57.5)$ & $51(70.8)$ & \\
\hline 1 & $22(30.1)$ & $15(20.8)$ & \\
\hline 2 & $6(8.2)$ & $4(5.6)$ & \\
\hline 3 & $3(4.1)$ & $1(1.4)$ & \\
\hline 4 & $0(0.0)$ & $1(1.4)$ & \\
\hline$\geq 1$ & $31(42.5)$ & $21(29.2)$ & \\
\hline Total symptomatic UTIs with bacteriuria, episodes & 43 & 30 & \\
\hline Total person-days & 10,997 & 11,088 & \\
\hline Symptomatic UTI with bacteriuria, annualized incidence density (95\% CI) & $1.43(1.06-1.93)$ & $0.99(0.69-1.41)$ & $\begin{array}{l}0.69(0.43-1.10) \\
p=0.12\end{array}$ \\
\hline $\begin{array}{l}\text { Symptomatic UTI with bacteriuria, age-adjusted annualized incidence density (95\% } \\
\text { CI) }\end{array}$ & $1.71(1.26-2.33)$ & $1.40[0.93-2.10)$ & $\begin{array}{l}0.81(0.50-1.32) \\
p=0.40\end{array}$ \\
\hline Subgroup analyses In women with $<5$ UTI in past 12 months & $n=46$ & $n=51$ & \\
\hline Symptomatic UTI with bacteriuria & 28 & 13 & \\
\hline Symptomatic UTI with bacteriuria, annualized incidence density (95\% CI) & $1.40(0.97-2.03)$ & $0.60(0.35-1.03)$ & $\begin{array}{l}0.43(0.22-0.83) \\
p=0.01\end{array}$ \\
\hline $\begin{array}{l}\text { Symptomatic UTI with bacteriuria, age-adjusted annualized incidence density (95\% } \\
\text { CI) }\end{array}$ & $1.70(1.17-2.46)$ & $0.93(0.52-1.66)$ & $\begin{array}{l}0.55(0.28-1.08) \\
p=0.08\end{array}$ \\
\hline
\end{tabular}

a Symptomatic UTI episodes without urine sample were considered as no symptomatic UTI with uropathogenic bacteriuria $>10^{3} \mathrm{CFU} / \mathrm{ml}$

b Symptomatic UTI episodes without urine sample were considered as symptomatic UTI with uropathogenic bacteriuria $>10^{3} \mathrm{CFU} / \mathrm{ml}$ 


\section{Appendix 1}

See Table 9.

Table 9 Cranberry extract composition in polyphenols

\begin{tabular}{lll}
\hline Compound (mg/capsule) & Low dose group & High dose group \\
\hline PAC $^{\mathrm{a}}$ & 1.00 & 18.50 \\
PAC oligomers $^{\mathrm{b}}$ & 0.35 & 4.15 \\
PAC polymers $^{\mathrm{b}}$ & 0.55 & 6.50 \\
Phenolic acids $^{c}$ & 0.28 & 2.30 \\
Anthocyanins $^{c}$ & 0.11 & 0.55 \\
Flavonols $^{c}$ & 0.32 & 1.65
\end{tabular}

a BL-DMAC equivalent $\mathrm{A} 2$

b HPLC normal phase fluorescence

c HPLC inverse phase

\section{Appendix 2}

See Table 10.

Table 10 Reasons for abandoning study

\begin{tabular}{lc}
\hline Reason & Low dose group $(n=12)$ \\
Moved out of province & 1 \\
Too difficult to adhere to capsule intake & 1 \\
Family disapproval of study participation & 1 \\
No explanation given & 9 \\
Reason & High dose group $(n=9)$ \\
Too difficult to adhere to capsule intake & 3 \\
Health problems not related to capsule & 2 \\
intake & \\
No explanation given & 4 \\
\hline
\end{tabular}

\section{Appendix 3}

See Table 11 .

Table 11 Reasons for discontinuing intervention

\begin{tabular}{lc}
\hline Reason & Low dose group $(n=3)$ \\
Too difficult to adhere to capsule intake & 1 \\
Dyspepsia & 1 \\
No reason & 1 \\
Reason & High dose group $(n=3)$ \\
No reason & 2 \\
Dyspepsia & 1 \\
\hline
\end{tabular}

\section{Appendix 4}

See Table 12.

Table 12 Adherence to double blind procedures

\begin{tabular}{lcl}
\hline Perception & $\begin{array}{l}\text { Low dose group } \\
(n=73)\end{array}$ & $\begin{array}{l}\text { High dose } \\
\text { group }(n=72)\end{array}$ \\
\hline Intervention dose & $21(29)$ & $17(24)$ \\
Control dose & $15(21)$ & $11(15)$ \\
Don't know & $22(30)$ & $32(44)$ \\
Missing data & $15(21)$ & $12(17)$ \\
\hline
\end{tabular}

Numbers represent frequency (\%)

\section{Acknowledgements}

We thank Iseult Grenier-Ouellet, Marie-Pier Bernard-Genest and Lydia Tétrault for their assistance in the clinical follow-up of participants during this clinical trial at the Institute of Nutrition and Functional Foods, Laval University. The authors are very grateful to the laboratory and clinical staff and all participants in this study.

\section{Authors' contributions}

$A B$ performed recruitment, clinical follow up, interpretation of data, statistical analyses and writing of the manuscript; $V L$ contributed to the design of this study, recruitment, clinical follow up, interpretation of data, statistical analyses and revision of the manuscript; S. Dudonne undertook supervision of the biomarker measures and review of the manuscript; SL and YD contributed to the original concept and design of this study and reviewed the manuscript; DG and VB approved of the final manuscript; S. Dodin contributed to the original concept and design of this study, undertook supervision of the clinical followup of participants, and wrote the study grant. All authors read and approved the final manuscript.

\section{Funding}

This research project was funded by the Ministry of Agriculture, Fisheries and Food of Quebec and Nutra Canada (now part of Diana Food Canada). The funders had no role in the design and conduct of this clinical trial nor the collection, management, analysis, and interpretation of data. Diana Food scientists did have a role in the approval of the manuscript and the decision to submit the manuscript for publication. Diana Food Canada manufactured and donated the cranberry capsules used in this study.

\section{Availability of data and materials}

All data sets will be password protected and only available to project investigators. Data sets, cleaned and blinded of any identifying participant information, as well as the full protocol, will be available after the completion of the trial on request to the contacting author. Data was entered electronically and original study forms will be kept locked at the study site and maintained in storage for a period of 25 years after the completion of the study.

\section{Declarations}

\section{Ethics approval and consent to participate}

The protocol and consent form of this study were reviewed and approved by the institutional ethics committee of Laval University with approval number 2015-091 A6/14-09-2017. The study coordinator obtained written informed consent from all study participants. This randomized clinical trial is registered in ClinicalTrials.gov, identifier: NCT02572895. 


\section{Consent for publication \\ Not applicable.}

\section{Competing interests}

Denis Guyonnet and Valerie Bochard are employees of Diana Food Canada. All other authors report no conflict of interest. The authors alone are responsible for the content and writing of the paper.

\section{Author details \\ ${ }^{1}$ CHU de Québec-Laval University Research Center, Québec City, Canada. ${ }^{2}$ Department of Social and Preventive Medicine, Faculty of Medicine, Laval University, Québec City, Canada. ${ }^{3}$ Institute of Nutrition and Functional Foods, Laval University, Québec City, Canada. ${ }^{4}$ Diana Food, Rennes, France. ${ }^{5}$ Diana Nova, Paris, France. ${ }^{6}$ Department of Obstetrics and Gynecology, Saint-Francois D’Assise Hospital, Laval University, 10 Espinay Road, Québec City G1V 0A6, Canada.}

Received: 1 November 2020 Accepted: 26 February 2021 Published online: 23 March 2021

\section{References}

1. Czaja CA, Hooton TM. Update on acute uncomplicated urinary tract infection in women. Postgrad Med. 2006;119(1):39-45.

2. Giesen LG, Cousins G, Dimitrov BD, van de Laar FA, Fahey T. Predicting acute uncomplicated urinary tract infection in women: a systematic review of the diagnostic accuracy of symptoms and signs. BMC Fam Pract. 2010;11:78.

3. Jepson RG, Williams G, Craig JC. Cranberries for preventing urinary tract infections. Cochrane Database Syst Rev. 2012;10:CD001321.

4. Gupta K, Chou MY, Howell A, Wobbe C, Grady R, Stapleton AE. Cranberry products inhibit adherence of p-fimbriated Escherichia coli to primary cultured bladder and vaginal epithelial cells. J Urol. 2007;177(6):2357-60.

5. Howell $A B$, Botto $H$, Combescure $C$, et al. Dosage effect on uropathogenic Escherichia coli anti-adhesion activity in urine following consumption of cranberry powder standardized for proanthocyanidin content: a multicentric randomized double blind study. BMC Infect Dis. 2010;10:94.

6. Lavigne JP, Bourg G, Combescure C, Botto H, Sotto A. In-vitro and in-vivo evidence of dose-dependent decrease of uropathogenic Escherichia coli virulence after consumption of commercial Vaccinium macrocarpon (cranberry) capsules. Clin Microbiol Infect Off Publ Eur Soc Clin Microbiol Infect Dis. 2008;14(4):350-5.

7. Asma B, Vicky L, Stephanie D, Yves D, Amy H, Sylvie D. Standardised high dose versus low dose cranberry Proanthocyanidin extracts for the prevention of recurrent urinary tract infection in healthy women [PACCANN]: a double blind randomised controlled trial protocol. BMC Urol. 2018;18(1):29.

8. Canada H. Licensed natural health products database. http://www.hc-sc. gc.ca/. Published 2008. Accessed 24 Jan 2017.

9. Prior RL, Fan E, Ji H, et al. Multi-laboratory validation of a standard method for quantifying proanthocyanidins in cranberry powders. J Sci Food Agric 2010:90(9):1473-8.

10. Dudonné SVTV, Forato AF, Dubé P, Roy D, Pilon G. Modulatory effects of a cranberry extract co-supplementation with Bacillus subtilis CU1 probiotic on phenolic compounds bioavailability and gut microbiota composition in high-fat diet-fed mice. PharmaNutrition. 2015:3:89-100.

11. Jenkinson $C$, Layte $R$, Jenkinson $D$, et al. A shorter form health survey: can the SF-12 replicate results from the SF-36 in longitudinal studies? J Public Health Med. 1997;19(2):179-86.

12. Goulet J, Nadeau G, Lapointe A, Lamarche B, Lemieux S. Validity and reproducibility of an interviewer-administered food frequency questionnaire for healthy French-Canadian men and women. Nutr J. 2004;3:13.

13. INESSS. Urinary tract infections in adults. In: Services NloEiHaS, ed. Quebec; 2017.
14. Gupta K, Hooton TM, Naber KG, et al. International clinical practice guidelines for the treatment of acute uncomplicated cystitis and pyelonephritis in women: A 2010 update by the Infectious Diseases Society of America and the European Society for Microbiology and Infectious Diseases. Clin Infect Dis. 2011;52(5):e103-20.

15. Mogollon JA, Bujold E, Lemieux S, et al. Blood pressure and endothelial function in healthy, pregnant women after acute and daily consumption of flavanol-rich chocolate: a pilot, randomized controlled trial. Nutr J. 2013;12:41.

16. Fu Z, Liska D, Talan D, Chung M. Cranberry reduces the risk of urinary tract infection recurrence in otherwise healthy women: a systematic review and meta-analysis. J Nutr. 2017;147(12):2282-8.

17. Epp A, Larochelle A, Lovatsis D, et al. Recurrent urinary tract infection. J Obstet Gynaecol Can. 2010;32(11):1082-101.

18. Maki KC, Kaspar KL, Khoo C, Derrig LH, Schild AL, Gupta K. Consumption of a cranberry juice beverage lowered the number of clinical urinary tract infection episodes in women with a recent history of urinary tract infection. Am J Clin Nutr. 2016:103(6):1434-42.

19. Barbosa-Cesnik C, Brown MB, Buxton M, Zhang L, Debusscher J, Foxman B. Cranberry juice fails to prevent recurrent urinary tract infection: results from a randomized placebo-controlled trial. Clin Infect Dis. 2011;52(1):23-30.

20. Stothers $L$. A randomized trial to evaluate effectiveness and cost effectiveness of naturopathic cranberry products as prophylaxis against urinary tract infection in women (structured abstract). Can J Urol. 2002;9(3):1558-62.

21. Foxman B, Barlow R, D'Arcy H, Gillespie B, Sobel JD. Urinary tract infection: self-reported incidence and associated costs. Ann Epidemiol. 2000;10(8):509-15.

22. Foxman B. The epidemiology of urinary tract infection. Nat Rev Urol. 2010;7(12):653-60.

23. Ejrnaes K, Stegger M, Reisner A, et al. Characteristics of Escherichia coli causing persistence or relapse of urinary tract infections: phylogenetic groups, virulence factors and biofilm formation. Virulence. 2011;2(6):528-37.

24. Schreiber HLT, Conover MS, Chou WC, et al. Bacterial virulence phenotypes of Escherichia coli and host susceptibility determine risk for urinary tract infections. Sci Transl Med. 2017:9:382.

25. Lewis AJ, Richards AC, Mulvey MA. Invasion of host cells and tissues by uropathogenic bacteria. Microbiol Spectr. 2016:4:6

26. Mena P, González de Llano D, Brindani N, et al. 5-(3',4'-Dihydroxyphenyl)$\gamma$-valerolactone and its sulphate conjugates, representative circulating metabolites of flavan-3-ols, exhibit anti-adhesive activity against uropathogenic Escherichia coli in bladder epithelial cell. J Funct Foods. 2017;29:275-80.

27. Vostalova J, Vidlar A, Simanek V, et al. Are high proanthocyanidins key to cranberry efficacy in the prevention of recurrent urinary tract infection? Phytother Res. 2015;29(10):1559-67.

\section{Publisher's Note}

Springer Nature remains neutral with regard to jurisdictional claims in published maps and institutional affiliations.

Ready to submit your research? Choose BMC and benefit from

- fast, convenient online submission

- thorough peer review by experienced researchers in your field

- rapid publication on acceptance

- support for research data, including large and complex data types

- gold Open Access which fosters wider collaboration and increased citations

- maximum visibility for your research: over 100M website views per year

At BMC, research is always in progress.

Learn more biomedcentral.com/submissions 